\title{
Ethnic and Religious Minorities and The Refusal to Vaccinate in Europe and USA
}

\section{K. Avery (Kirsty Avery)1', M. Palenikova (Milica Palenikova)²}

${ }^{1}$ Panuska School of Professional Studies, Scranton PA, USA.

${ }^{2}$ St. John Paul II Institute of Missionary, Bratislava, SK.

\section{E-mail address:}

pechacova.daria@gmail.com

\section{Reprint address:}

Daria Kimuli

MSE PhD, Nairobi

Kenya

Source: Clinical Social Work and Health Intervention

\section{Reviewers:}

Daria Kimuli

MSE PhD, Nairobi, Kenya

Michael Costello

University of Scranton School of Education, USA

\section{Keywords:}

Vaccination, Religion.

\section{Publisher:}

International Society of Applied Preventive Medicine i-gap

CSWHI 2020; 11(2): 5 - 8; DOI: 10.22359/cswhi_11_2_01; C Clinical Social Work and Health Intervention

\section{Abstract:}

Religious facts in the refusal of vaccination are repeated worldwide.

METHODS: The aim of this presentation is to analyse religious/ethnic risk factors for vaccination problems.

RESULTS: The number of refusal events is increasing mainly in high resource/income countries.

CONCLUSION: Legislation, education, interreligious dialogue are advisable in prevention of the increase of unvaccinated children. 


\section{Introduction}

Low rates of vaccination within specific groups has been reported (1-5) in Amish, Orthodox, Jewish, Roma, Mennonites and other religious/ethnic groups and can potentially leads to the spread of disease outbreaks. Researching attitudes, beliefs, religious views, medical reasons, etc. may help us to better understand the complexity of the problem of decreasing vaccination rates in developed high resource countries.

United States:

\section{Measles Cases Reported by Month in 2019}

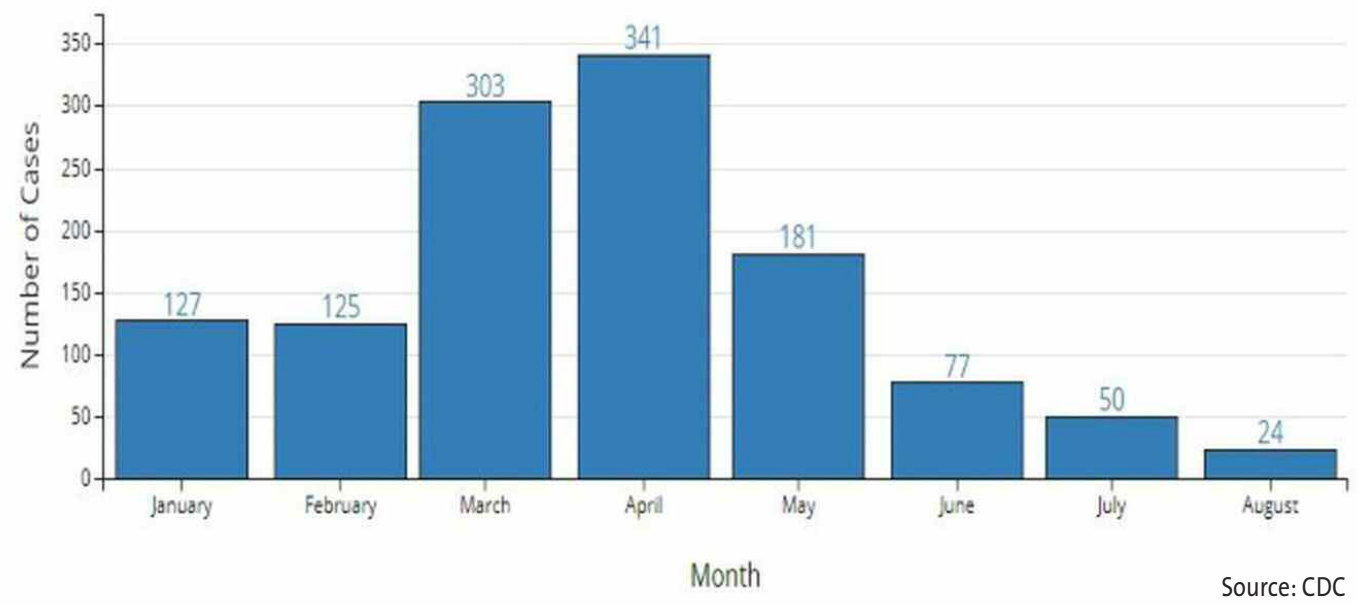

From the beginning of the year through Thursday, 1,241 individual cases of measles have been confirmed in 31 states, the CDC said.

\section{United States:}

NUMBER OF MEASLES CASES REPORTED BY YEAR $2010-2018 *$ (as of December 29, 2018)

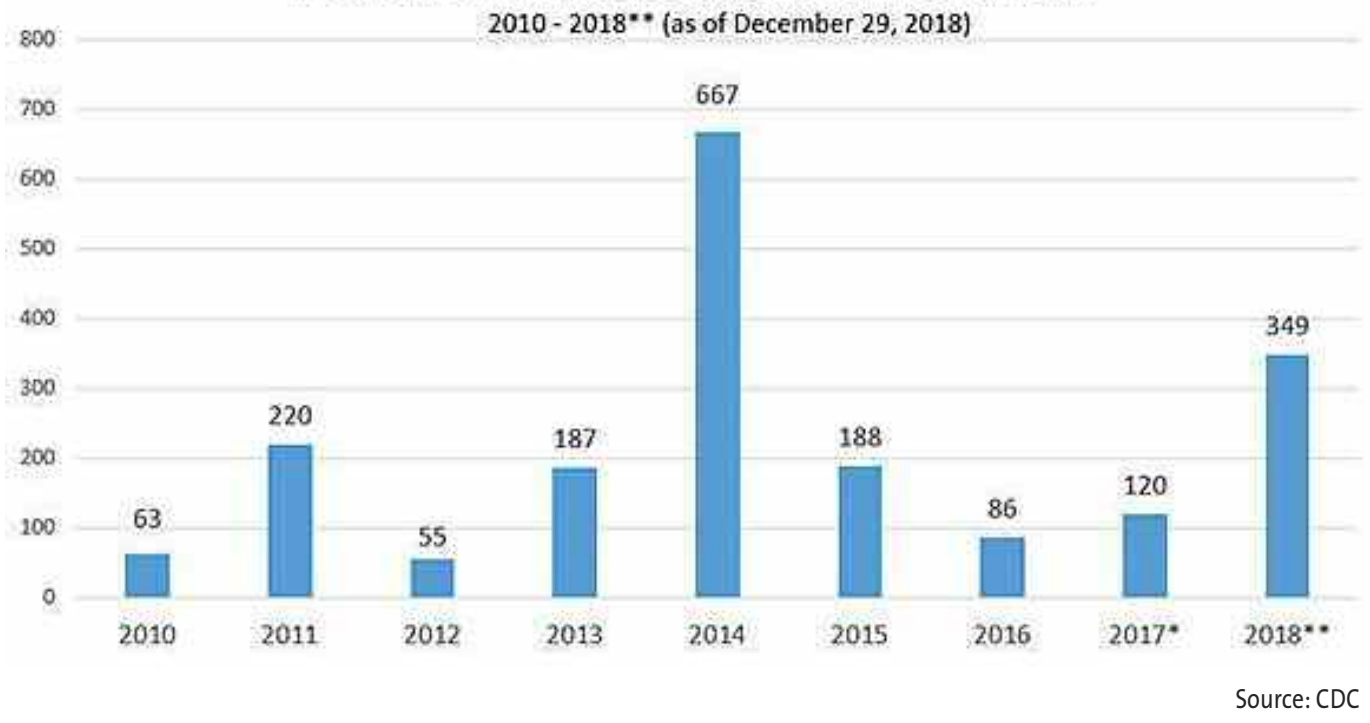

Graphic above shows the number of measles cases reported by year since 2010 . 


\section{Reasons for Current Outbreaks}

Tourism and immigration are known risk factors for failure of elimination of diseases which are known as partially or completely eliminated/eradicated (Polio, measles, diphtheria etc.): in Israel polio; Ukraine measles; Philippines diphtheria. Perception of parents may be strongly influenced by religion/ethnic habits. Lack of perceived importance is observed as well. Financial issues usually play only very minor roles. Health provider perception (for said groups) may be pooled as well.

\section{Importance of Vaccination}

In 2017, there were 110,000 measles deaths globally, mostly among children under the age of 5. Measles vaccination resulted in an $80 \%$ drop in deaths between 2000-2017 worldwide. In 2017 , about $85 \%$ of the world's children received one dose of measles vaccine by their first year through routine health services - up from $72 \%$ in 2000. During 2000-2017, measles vaccination prevented an estimated 21.1 million deaths (WHO 2019).

\section{Amish Communities}

Amish Communities are groups of traditionalist Christian Church fellowships. Their approximate population is 330,270 with an estimated $68 \%$ vaccinated; childhood immunization rate is low; information regarding the decision to vaccinate is insufficient. According to the 10 years study of Penn State Children's Hospital 215 Amish children $=8 \%$ were vaccinated; unvaccinated were twice more likely to experience hospitalization. (American Journal of Epidemiology, 2018).

\section{Mennonite Community}

Observations are very similar to Catholic/Amish values. Estimated population in US is 308,030 , globally 1 million. They do not seek healthcare until they are very sick or if their ability to work is limited. Medical advice they seek from other community members. They prefer natural remedies and immunization in this community is limited. (Armer,J.M., Radina, M.E. 2006).

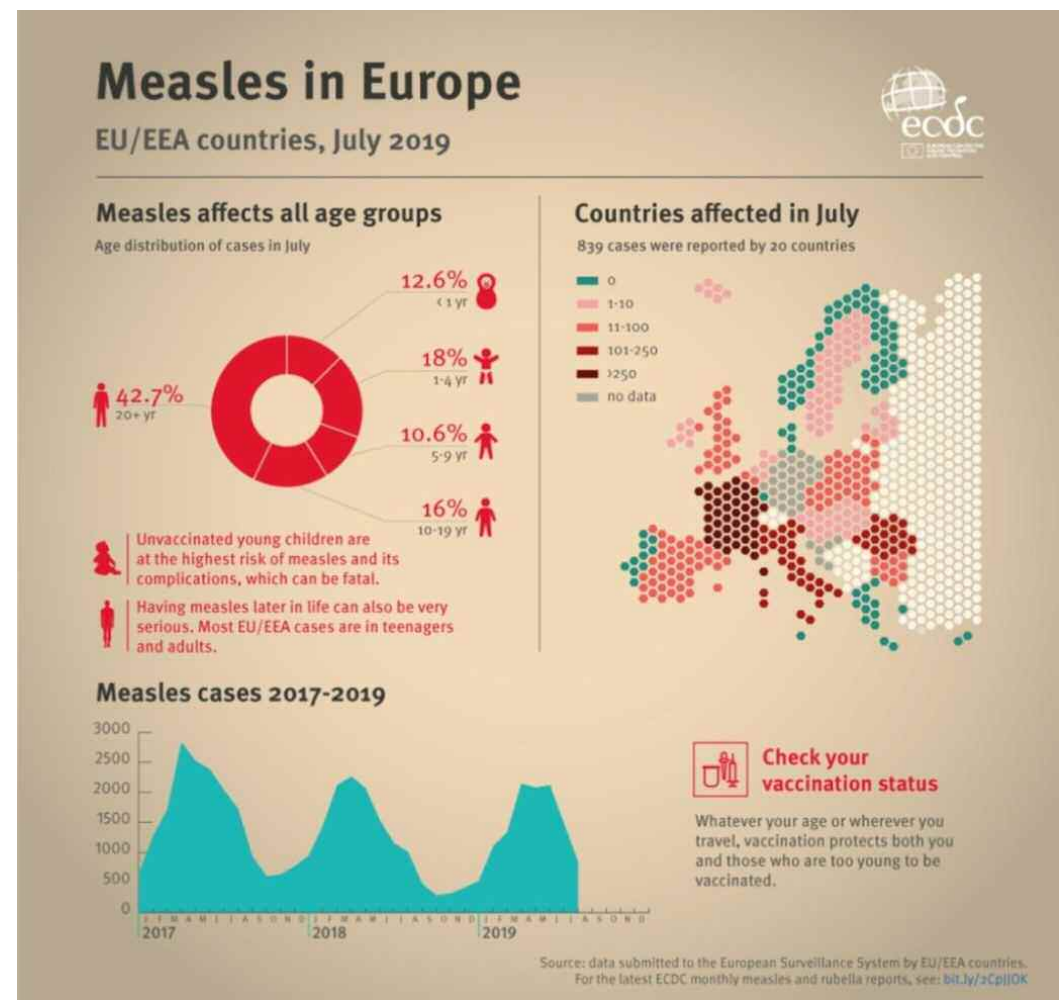




\section{America's biggest recent measles outbreaks}

2010-2018 (as of October 6, 2018)

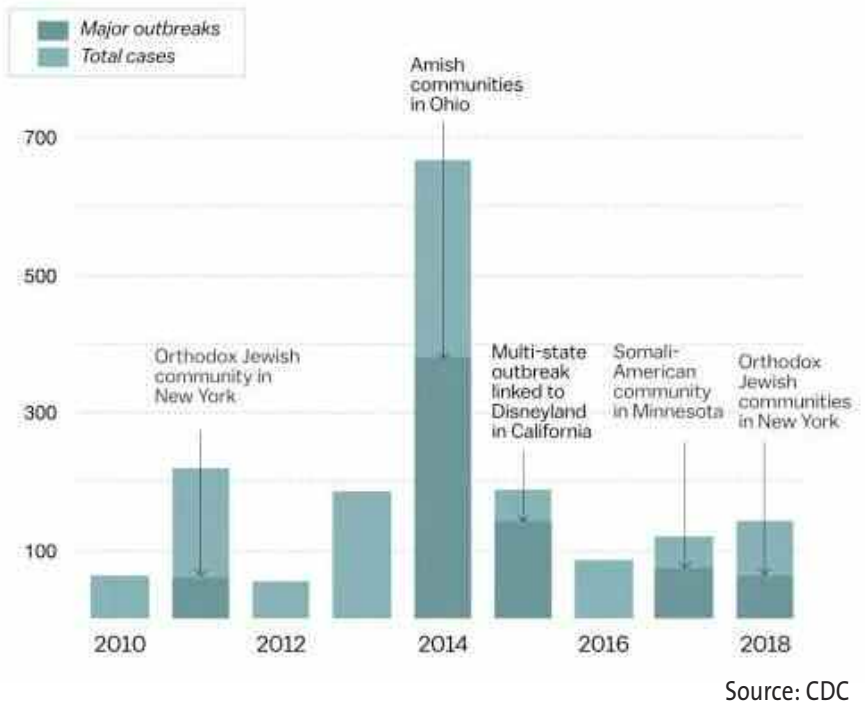

\section{Orthodox Jewish community}

Members of this religion share religious observance and cultural practices. They live closely within their own communities: in London 200,000 members; Salford UK 10,000 members; Atwerp, Belgium 15000 members; USA 6.9 million. Study shows a vaccination coverage of $79 \%$. Many outbreaks were epidemiologically linked to Israel.(Lernout T. et al. 2009)

\section{Roma population}

There is 6-8 million Roma people in Europe. Among them vaccination is very low. According to the study of 251 Roma children $39 \%$ had minimum vaccination. There is insufficient information regarding the decision to vaccinate. Living in poor economic conditions and improper housing leads to potential spread of disease. (Fournet et al. 2018) (Papamichail et al.2017).

\section{References:}

1. AMERICAN JOURNAL OF EPIDEMIOLOGY (2018) https://academic.oup.com/aje/article/187/9/2002/4964639.
2. ARMER, JM, RADINA, ME (2006) Definition of Health and Health Promotion Behaviors Among Midwestern Old Order Amish Families. The Journal Of Multicultural Nursing \& Health 12:3 Fall 2006, p.44-53, ISSN 1043-6596.

3. LERNOUT T ET AL (2009) An outbreak of measles in orthodox Jewish communities in Antwerp, Belgium, 2007-2008: different reasons for accumulation of susceptibles. PuMed, US https://www.ncbi.nlm.nih.gov/pubmed/ 19161716.

4. FOURNET ET AL (2018) Roma Vaccinations Study Public Health.

5. PAPAMICHAIL ET AL (2017) Roma Vaccinations Study European Journal of Public Health. Measles and Data Statistics 2019. CDC the Centers for Disease Control and Prevention, Atlanta, GA 2019. https://www.cdc. gov/measles/downloads/measlesdataandstatsslideset.pdf. 